\title{
On the Application of Incentive Mechanism in Human Resource Management
}

\author{
Mingxin Yu \\ Gachon University, Korea
}

\begin{abstract}
With the gradual deepening of China's market economic system reform, the macro social economy has entered a period of rapid development, and the competition among modern enterprises has become increasingly fierce. In essence, the core of modern enterprise competition is the competition of talents, which further highlights the necessity of human resource management, and incentive mechanism as an important component, whether it can be effectively used is particularly important. The research on related topics has attracted much attention and heated discussion. Based on the summary and analysis of the construction principle of incentive mechanism, this paper probes into the current situation and optimization of its application in human resource management.
\end{abstract}

Keywords: enterprise development; human resource management; incentive mechanism; optimize

\section{Introduction}

Under the ecological pattern of economic globalization and China's market economy system reform, the competition among modern enterprises has entered a white-hot stage, which is reflected in material resources, financial resources, technology, talent and many other aspects.Among them, the core position of talents in enterprise competition is more and more prominent, and affects the long-term development of enterprises.How to retain talents, develop talents and use talents are the problems that enterprises must consider to achieve the strategic goal of sustainable development.This series of contents constitute the human resource management system, whose effectiveness depends on the perfection of the enterprise's incentive mechanism.

\section{Construction Principle of Incentive Mechanism}

From the perspective of psychology, motivation refers to the process of stimulating and strengthening people's motivation, and then guiding and promoting their behaviors in order to achieve the desired goal. As an important part of human resource management, motivation is of great significance to the promotion of employees' enthusiasm and creativity, and is a key link to the realization of organizational goals. It is based on the effectiveness of motivation in human resource management, whether it can be effectively organized and practiced is crucial, which is also closely related to the age, gender, education background and experience of employees. Relevant mechanism construction should follow the systematic principle, comprehensively review the behavior practice of employees, attach importance to give play to their individual role, so as to improve their business level. At the same time, according to maslow's demand theory, employee demand presents a trend of diversification. In the people-oriented perspective, the diversity of incentive mechanism should

Copyright (C) 2019 by author(s) and Frontier Scientific Research Publishing Inc.

This work is licensed under the Creative Commons Attribution International License (CC BY 4.0).

http://creativecommons.org/licenses/by/4.0/ 
be emphasized, including spiritual incentive, material incentive, promotion incentive, training incentive, etc., so as to improve their satisfaction and maximize their positive management role. In addition, under the socialist social ecology, democracy and fairness are the core of modern enterprise human resource management. We should stress the transparency construction of incentive mechanism. Through horizontal and vertical comparison, positive incentive and negative incentive should be paid equal attention to ensure fairness, reduce or even avoid employee resistance, so as to promote the realization of the strategic goal of sustainable development of the enterprise. In a certain dimension, the core of motivation is to improve employees' job satisfaction. Only under the guidance of human nature, fairness, democracy and other principles, can the incentive mechanism give full play to its effectiveness.

3. The Application Status of Incentive Mechanism in Enterprise Human Resource

\section{Management}

Under the background of market economy system reform, modern enterprises are facing more and more severe challenges of survival and development, and their dependence on human resources is becoming increasingly prominent. In fact, in the long-term innovative exploration and practice, many enterprises have gradually established a relatively complete incentive mechanism for human resource management, and achieved remarkable results. However, in the face of the increasingly diversified demand dynamics of employees, many problems are also exposed, which reduces the effectiveness of human resource management and hinders the goal of sustainable development of enterprises. To be specific, with the development of social economy, people's quality of life has been improved, at the same time, they also show more strong material needs and desires, in order to obtain better living conditions. However, some enterprises, especially private enterprises, pay too much attention to the pursuit of their own interests and ignore the individual interests of employees. There is a certain imbalance between labor and effort, and the lack of material incentive further intensifies the contradiction between the two. At the same time, enterprises often ignore spiritual and cultural incentives due to the nature of pursuing economic interests, which weakens employees' sense of belonging and identity. In addition, the balance between positive and negative incentives in some enterprises is insufficient, and the design of performance appraisal mechanism is not perfect. For example, the adoption of annual assessment and the lack of daily assessment leads to the distortion and lack of objectivity of relevant feedback results, which affects the career development of employees and weakens the market competition level of enterprises.

\section{The Use of Incentive Mechanism in Human Resource Management Optimization Strategy}

The application of incentive mechanism in human resource management is the key way to stimulate people's enthusiasm and initiative. As a systematic practice project, we should attach importance to the optimization and construction of multiple links to maximize its inherent value. Based on the above analysis and combined with the actual situation, the following several optimization strategies are proposed for reference.

\subsection{Strengthening safeguard support}

Under the operation ecology of market economy system, the core capital of modern enterprise competition is undoubtedly talents. Effective management mode can give full play to its inherent value to the greatest extent, thus laying a foundation for realizing the strategic goal of sustainable development. As an indispensable part of human resource management system, incentive is a key means to release people's subjective initiative, and the construction of relevant operating mechanism should be supported by enterprises. Therefore, enterprises must attach great importance to human resources management in the new period, keep up with the trend of The Times, constantly emancipating the mind, relying on the people-oriented idea guidance, combined with their own actual situation, continuous innovation to optimize the relevant institutional framework, understanding staff demand dynamic, scientific and reasonable forecast, for the next 
phase of the incentive mechanism provides a new starting point. At the same time, companies also need to emphasize on the internal construction of humanistic environment, outstanding talent actuates the core strategy in the development of consciousness, as a whole to form a kind of respect for talent, advocating knowledge working atmosphere, and moderately increased investment in related aspects of the construction, improve the working environment and conditions, to make it under a relatively relaxed state of body and mind in a more positive emotions into work, and then output the larger professional value, realize the two-way synchronous development of individual and enterprise. In addition, no rules can not square, any period of management is inseparable from a sound system of security and support. Therefore, enterprises need to further improve the relevant supporting systems of human resource management, and clarify the incentive principles, standards, procedures and other contents.

\subsection{Multiple modes}

According to maslow's needs theory, human needs generally include physiology, safety, emotion, respect and selfactualization, and show a hierarchical relationship. When people's basic needs are met, they will move towards higher levels of needs, which is also the fundamental driving force for the continuous development of human society. It is the constant pursuit of employees that drives them to work tirelessly to meet their diverse needs. The application of incentive mechanism in the enterprise human resources management should respect the general rules of diversified needs for employees, take the material incentive and spirit incentive pay equal attention to, positive incentives and negative incentives for way, enriched the contents of the related project and combined with the examination content and employee demand tendency, give the appropriate incentives, to maximize the release of its application value. In the specific practice process, enterprises should break the stereotype of seniority, delegate management authority to employees, and guide them to participate in the formulation of incentive rules, so as to win more trust from them. Meanwhile, humanistic care should be emphasized to ensure the fairness and transparency of incentives. We should be good at discovering outstanding employee deeds, set an example, and give its appropriate material reward and spiritual reward, in order to infect all employees to forge ahead together. In addition, to organize various stylistic practice, strengthen the construction of employee ideas, strengthening the professional ethics, professional quality, etc., enhance their collective sense of honor, inspire them to contribute own strength of sustainable development for the enterprise, the concept of connected to actively participate in the enterprise management, and then open the bright future of individual and enterprise. Finally, we should give full play to the restraint function of negative incentive, regulate the behavior of employees and purify the bad atmosphere inside the enterprise.

\subsection{Improve assessment and training}

The perfect performance appraisal mechanism is the basis of human resource management and can provide necessary information basis. In the process of concrete practice, perfect the mechanism of performance appraisal, shall uphold the principle of fairness and justice, objective and comprehensive guide, organically combine daily assessment and year-end appraisal, and pay attention to guide employees to actively participate in, to form a good internal management ecology, motivate employees to a certain extent self-discipline and development. The setting of daily assessment items should include work attitude, professional quality, professional ethics, team spirit and other contents. At the same time, we should be good at digging out the outstanding employees' deeds, find out the existing problems in time, deal with them timely and effectively, embody the principle of human resource management to stimulate equity, and stimulate the development activity of employees. Based on this, to organize diversified training education activities, to invite industry experts widely participation, the outlook for enterprise future development prospect, and is closely related with employee career development planning, update their ideas, enrich their knowledge structure, sharing effective practical work experience, 
improve their overall quality level, and to create more value, finally gradually meet the objective of its various aspects. In the specific way of organization, employees should be pleased with the way, such as lectures, audio-visual discussion, study abroad, so as to play a multiplier effect with half the effort. In addition, the enterprise also needs to go to the bottom of the employees, understand their career development needs, help and guide them to make appropriate plans, and give them necessary support, enhance their development confidence, enhance the sense of dependence on the enterprise.

4.4Pay structure adjustment

Compensation management is an important module of enterprise human resource management system, which is closely related to the immediate interests of employees and the basic guarantee for their survival. A scientific and reasonable compensation structure should be closely related to the development strategy of the enterprise, so as to motivate the unification of employees' personal goals and enterprise goals, so as to achieve mutual benefit and win-win results. Especially in the current relatively open and free Internet social ecology, employees' independent choice has been greatly released. The adjustment and optimization of salary structure is a key means to retain excellent talents and give full play to their effectiveness. Generally speaking, the common salary system of enterprises includes post salary system, skill salary system, performance salary system and structure salary system, etc., and their advantages and disadvantages are relatively obvious. Due to the personality differences between people, and in different stages of development, the demand structure is very different, and the choice of appropriate compensation incentive mechanism is crucial. In this regard, this paper suggests that enterprises should choose flexible compensation system, which is related to employees' job position, job performance, job skills, education level and contribution, and focus on structural salary system, so as to stimulate employees' work activity. In this process, the compensation structure should include external compensation, internal compensation and welfare compensation. Among them, exterior salary basically is to point to base salary, length of service salary, technology salary, academic record salary. And intrinsic salary lays more stress on the psychological satisfaction of employees' diligence and hard work, which can enhance their sense of pride, achievement and honor. Welfare salary refers to a kind of material compensation for employees, such as "five social insurance and one housing fund", which is an effective way to stabilize the sustainable development of employees and make contributions to the enterprise.

\section{Conclusions}

In a word, the use of incentive mechanism in human resource management is very important and necessary, is the key to maximize the value of talent. In the specific work organization, the enterprise should be enough attention and support. We should constantly enrich the content of relevant projects, pay equal attention to spiritual incentive and material incentive, give equal weight to positive incentive and negative incentive, strengthen the assessment and training, adjust the salary structure, so as to meet the diverse needs of employees and further release their work initiative.

\section{Conflicts of Interest}

The author declares no conflicts of interest regarding the publication of this paper.

\section{References}

[1] Gu X.J. (2019). Application of Incentive Mechanism in Enterprise Human Resource Management. Market Modernization, 18, 120-121.

[2] Yu W.C. (2019). On the Application of Incentive Mechanism in Enterprise Human Resource Management, Human Resources, 16, 113-114.

[3] Jia N. (2019). On the Importance of Incentive Mechanism in Human Resource Management, Guangxi Quality Supervision Guide, 9, 38. 
[4] Dai E.L. (2019). Discussion on Measures to Strengthen the Construction and Application of Incentive Mechanism in Enterprise Human Resource Management, Enterprise Reform and Management, 17, 90+92.

[5] Zhang J.P. (2019). Discussion on the Application of Incentive Mechanism in Enterprise Human Resource Management, Chinese and Foreign Entrepreneurs, 26, 98-99+110. 